\title{
Exurban residential subdivision development: Effects on water quality and public perception
}

\author{
JOAN IVERSON NASSAUER \\ J. DAVID ALLAN \\ THOMAS JOHENGEN \\ SANDRA E. KOSEK \\ DANA INFANTE \\ School of Natural Resources and Environment, University of Michigan, Ann Arbor 48109, USA
}

nassauer@umich.edu

\begin{abstract}
We investigated how future alternative designs for exurban residential subdivision development in agricultural landscapes might affect aquatic ecosystems and public perceptions, and we asked whether better aquatic ecological quality would correspond with public perceptions of greater landscape attractiveness. The alternative exurban futures we compared were: ecologically beneficial subdivisions, conventional subdivisions, and conventional agriculture. To judge their aquatic ecology effects we measured the chemistry and biota of six first-order streams within our study area, the Huron and Raisin River watersheds in the Detroit CMSA. We chose two stream catchments that exhibited land cover to represent the same proportions as each of three types of alternative exurban futures. Streams in catchments representing ecologically beneficial subdivision designs had the most total macroinvertebrate taxa, the most sensitive macroinvertebrate taxa, lowest nitrates, lowest total phosphorus, and lowest total suspended materials. Nutrient concentrations were highest in agricultural catchments, and suspended sediments were highest in conventional subdivision catchments. To compare public perceptions of the alternative futures, we surveyed 336 suburban and exurban adult residents of the upper Midwest. All respondents viewed digital imaging simulations of each of the futures and rated their attractiveness as if they were seen from the window of a home in the area. Ecologically beneficial futures were perceived as most attractive. Comparing the alternative futures, rankings of aquatic ecological quality were consistent with public perceptions of attractiveness.
\end{abstract}

Keywords: watershed, landscape, agriculture, sprawl, web-based survey

\section{Introduction}

To examine how future exurbanization could affect the ecological function of landscapes and aquatic ecosystems, we conducted an empirical investigation of alternative landscape futures for unsewered residential subdivisions in southeastern Michigan stream catchments. We compared future residential alternatives designed to have expected ecological benefits, futures that reflect conventional residential development patterns, and conventional agricultural futures. While exurban development patterns are the subject of great interest in modeling metropolitan development patterns, their empirical performance is only beginning to be tested (Alberti, 1999). Strengthening the empirical basis for modeling ecological and social effects of exurban development can improve the quality and utility of urban growth models. Having an empirical basis for making claims about the ecological success and social acceptability of future innovative development patterns also can assist decision makers in adopting these innovations. 
Making this link requires bringing design and planning into the realm of science, but this is difficult partly because design and planning tend to work with particular landscapes imagined for the future, while science tends to address generalizable landscape characteristics observed in the past or present. In addition, landscape science often relies on geographic information systems (GIS) data bases that describe land use/land cover at coarse resolutions compared with the much finer resolutions employed in landscape design and actual site construction. Fine scale design decisions about storm water movement or planting design are unlikely to appear on coarse scale data bases, but could have significant aggregate ecological effects (Hunsaker and Levine, 1995; Gove et al., 2001).

Finally, definitive qualities from the perspective of design include public perception (do people find a landscape attractive?), while definitive qualities for the same landscape from the perspective of science include ecological characteristics, which may or may not be related to public perception (Steinitz, 1990; Nassauer, 1992; Gobster, 1999). A central difference between public preference and ecological quality relates to landscapes that display apparent human care (Nassauer, 1995). While the public tends to prefer landscapes that look well cared-for, ecologically healthy stream corridors sometimes look "messy" to the unknowing eye (Nassauer et al., 2001). For example, Gregory and Davis (1993) found that the public prefers the appearance of river channels that are not cluttered by woody debris. Similarly, both Kaplan (1989) and House and Sangster (1991) found that mown grass landscapes were preferred to those featuring tall grass along stream banks.

While both landscape science and landscape design affect landscape change, their differences in image (imagined or observed), time frame (future or past/present), scale (fine or coarse), and definitive characteristics (perceptual and ecological) can lead to very different conceptual frameworks. In this investigation, we linked these frameworks by developing generalizable designs for future landscapes, by using landscapes that exist in the present to measure characteristics we proposed for future landscapes, by measuring at a fine scale aquatic ecological functions that are typically extrapolated to a coarse scale, and by comparing ecological and public perception measurements of the same landscape futures. We used an alternative future landscape scenario approach to develop generalizable designs (Nassauer and Corry, 2004). We used space for time substitution to assess the possible effects of alternative future exurban residential subdivision designs on water quality. To measure water quality attributes that could be associated with different exurban development patterns, we selected bioassessment protocols for aquatic characteristics that might be expected to vary across first order watersheds (Barbour et al., 1999). To assess the alternatives' possible effects on stream chemistry, we identified first-order catchments in our study area that exhibited land cover to represent the same proportions as the alternative futures, and we measured the chemistry of the first-order stream in each catchment. To assess public perceptions of the alternatives, we conducted a web-based survey in which 336 suburban and exurban adult residents of the upper Midwest (primarily southeast Michigan) were presented with digital imaging simulations of the alternative futures. This strategy allowed us to test ecological concepts for metropolitan exurban design in interdisciplinary research at the interface of landscape design and aquatic ecology.

This investigation is part of a larger study intended to help decision-makers anticipate the ecological effects and perceived cultural and economic value of landscape change in 
exurbanizing landscapes. The larger study investigates: (1) landscape variables that predict stream degradation, (2) alternative ecological design strategies for exurbanizing areas, and (3) implications for land use policy, design, and management ${ }^{1}$.

Modeling of hydrologic functions within metropolitan watersheds has consistently demonstrated that planning for ecological benefits can improve the water quality of rivers (Hulse et al., 2000; Crowder and Diplas, 2002; Martin et al., 2002), but these studies exhibit some of the disjunctions between science and planning that we described above. They are calibrated or validated against past land use/land cover patterns and use relatively coarse data. Their focus is on alternative patterns of land use rather than on alternative land cover designs within a land use type. Water quality effects are modeled as a function of percentage of impervious surface associated with a land use type. Hydrologic models predicting water quality effects of land cover change are calibrated on existing land covers associated with current land uses rather than on alternative future land covers for land use types. Within the hydrologic models, broad land cover classes represented at coarse scales (e.g. urban, agriculture, forested) are assumed to have distinct hydrologic characteristics such as curve number values associated with imperviousness (e.g., Miller et al., 2002). More than 25\% impervious cover has been widely adopted as a rule-of-thumb for anticipating degradation of water quality (Schueler, 1994; Cappiella and Brown, 2001).

While imperviousness has been found to correlate well with measures of stream quality at broad watershed scales (Arnold and Gibbons, 1996), and has been modeled as a characteristic of urban land use as it relates to stream biology (Klein, 1979; Wang et al., 2001), aquatic habitat (Booth and Jackson, 1997), and hydrology (Booth and Jackson, 1997), the relatively fine scale of residential subdivision design, compared with the coarser scale of larger watershed models, may affect model outcomes (Gove et al., 2001). Imperviousness has seldom been investigated as a fine-scale variable within a land use type, and where it has been investigated, the focus was: suburban residential densities served by sewer and water infrastructure (Girling and Kellett, 2002), storm water best management practices in no specific design or pattern, i.e., spatially distributed uniformly across residential land use (Jia et al., 2002), or measurement of land cover change over time without reference to a generalizeable design or planning typology (Jennings and Jarnagin, 2002). Our water quality approach is most similar to Burges et al. (1998), who present an example of a hydrologic model at a fine scale, that of a zero-order catchment with intermittent drainage (ranging in size from 0.2 and $0.4 \mathrm{~km}^{2}$ ). They compared two catchments, one draining undeveloped forest and the other draining a (conventional) subdivision. Their intent was similar to ours in that they wanted to capture the land phase of the hydrologic cycle at the incremental scale at which the land use change occurs, and they found that the percentage of annual precipitation that becomes runoff was 12 to $30 \%$ in the forested catchment compared with 44 to $48 \%$ in the suburban catchment. Our study design, substituting space for time, allows us to make further inferences for future landscapes from our field data in that we chose catchments that were landcover analogs for our alternative future design scenarios.

Several planners and designers have designed residential development to have ecological benefits, and some employ storm water management to improve hydrological function (e.g., Arendt, 1996; Arendt, 1999; Nassauer, 1999; Steiner et al., 1999; Forsyth, 2002; 
Girling and Kellett, 2002). However, the ecological effects of these design strategies have not been measured and reported, and consequently, could not be calibrated for models at a watershed scale. In addition, public perception of these designs has not been measured. Our study tests for the potential water quality and public perception effects of such ecologically beneficial exurban development alternatives. It asks: "Can exurban residential development be designed to deliver ecological benefits, and if so, will the public find it attractive?"

\section{Method}

\section{Study area}

Our study area is the adjacent Huron (2350 km sq.) and Raisin (2780 km sq.) River Basins, which lie west and south of Detroit in southeastern Michigan. Early in the 19th century both regions were primarily deciduous forests with scattered wetlands. While the Huron River Basin was 25\% agricultural land use in 1997, the Raisin remained 63\% agricultural. The population of many exurbanizing townships within the study area grew by more than 40\% between 1990 and 2000 (Southeast Michigan Coalition of Governments 2001, from U.S. Census 2000). Consequently, to anticipate ecological effects on study area streams, we examined alternative future forms of exurban residential development, the primary type of extensive land use change in the region.

\section{Alternative landscape futures}

To consider alternative forms of future residential exurban development within the study area, we described two alternative future exurban subdivision scenarios: one, a conventional scenario in which individual parcels larger than five acres accommodate individual septic systems and wells and in which indigenous plants and ecosystems are not intentionally included in the subdivision; and the second, an ecologically beneficial alternative, described below. Then, we designed two exemplary subdivision design examples, or futures, for each of these scenarios (Nassauer and Caddock, 1997). We designed our alternative subdivision futures for both a 370 -acre parcel and a 90-acre parcel, so that each scenario was designed as two alternative futures for each of the two parcels. We used the plan futures to calculate percentages of landcover typical of each type of future. Then, we digitally simulated the view of each future as seen from the window of a home in the subdivision (figures 1 and 2 ); and we used these simulated views as the stimuli in our survey of public perceptions of each future. Our overriding goal in designing the ecologically beneficial futures was:

- to maintain the open, rural character of exurban areas,

- to enhance habitat by increasing patch size, connectivity, and regeneration of indigenous ecosystems,

- to improve water quality, flow regimes, and aquifer recharge by reducing inputs of fertilizers, herbicides, and pesticides, and by detaining, cleaning, and infiltrating storm water. 


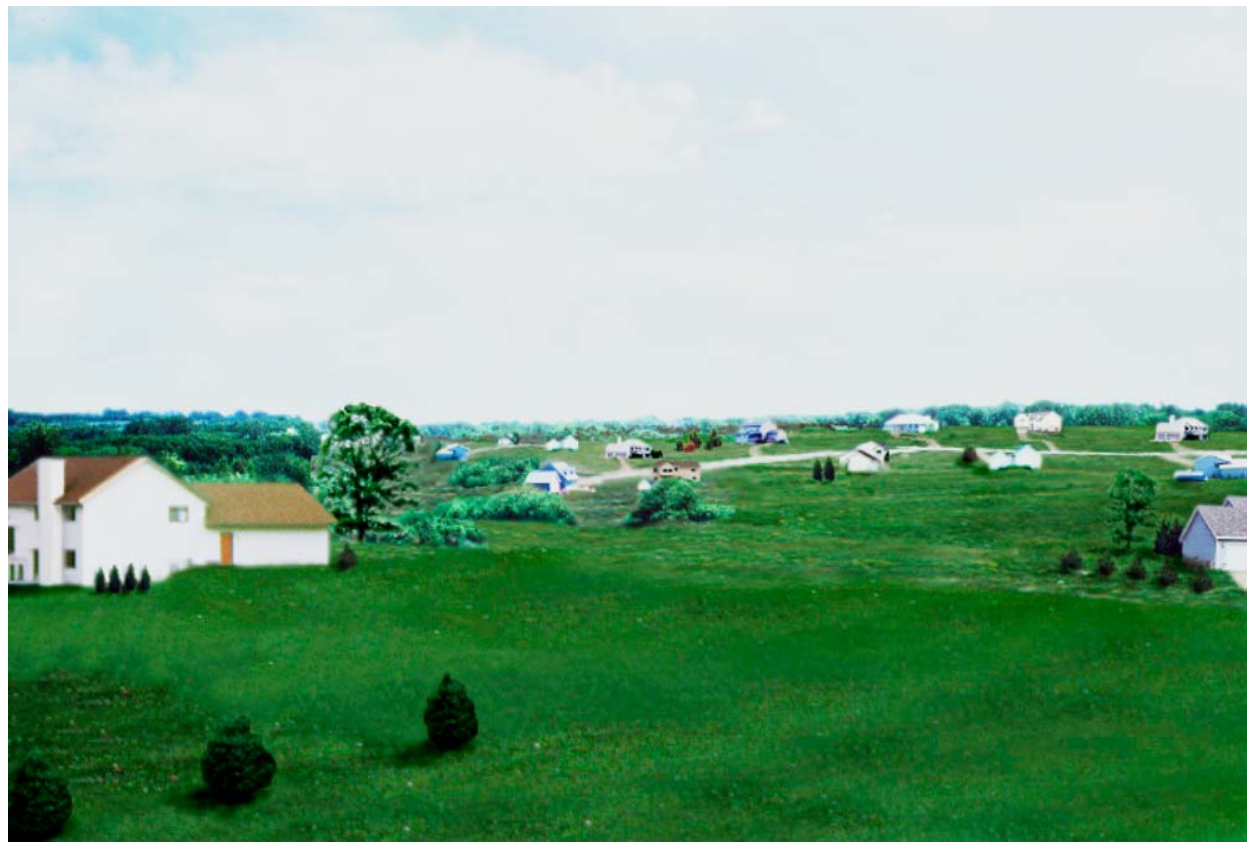

Figure 1. Simulation of one of two replications of the conventional development scenario.

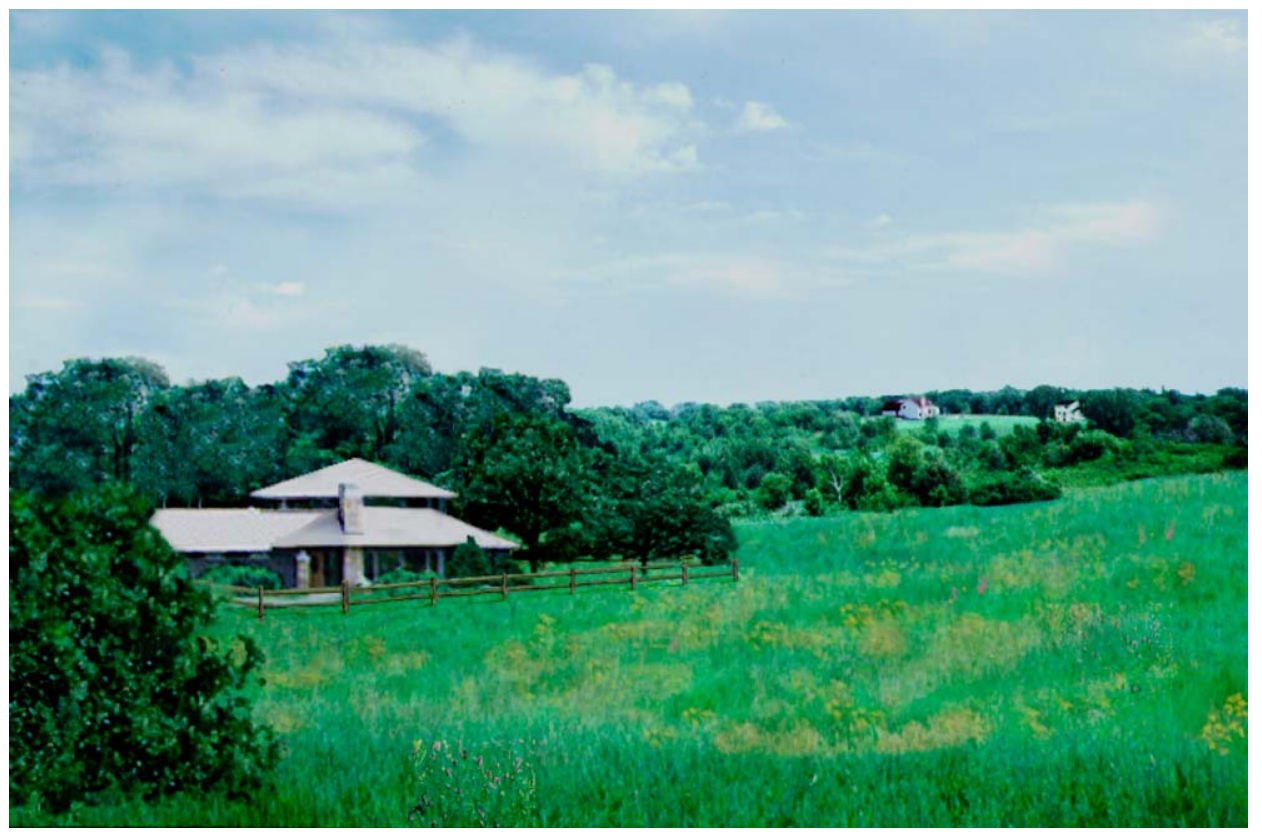

Figure 2. Simulation of one of two replications of the ecologically beneficial scenario. 
We did not aim for other important ecological goals that are more relevant to residential development in sewered areas (e.g., high density), or other important societal goals, like affordable housing. Rather, we accepted that some exurban development will be expensive residential development without city sewer or water services, and, we investigated how this type of development could be used to produce larger, dramatic public ecological and open space benefits. Elsewhere Nassauer and Caddock (1997) explored alternatives including more affordable housing at a higher density on sewered lots under the same base landscape conditions. For this investigation, we employed both ecologically beneficial and conventional subdivision development scenarios with two replicate futures on each scenario $(n=4$ futures), all of which accepted low residential densities and assumed private septic systems and wells.

Conventional large lot landscape futures (figure 1) were characterized by five to ten acre (2-4 ha) lots that do not include patches of indigenous vegetation. This lot size is a minimum under agricultural zoning in many townships that are undergoing exurban development in the study area. Removing all indigenous vegetation except protected wetlands and some individual trees is typical of conventional residential development. Road density for this scenario averaged 2.56 linear miles per 640 developed acres ( 259 ha).

Ecologically beneficial landscape futures (figure 2) were characterized by twenty to forty acre (8-16 ha) lots (gross density), with the overall subdivision land cover characterized predominately by restored or maintained indigenous vegetation. In one replication, the footprint of buildings, paving, and mown turf is less than one acre $(0.4 \mathrm{ha})$, individually owned lots are twenty to forty acres (8-16 ha), and footprints are not clustered. In the other replication, ten to twenty one-acre ( $0.4 \mathrm{ha})$ lots are clustered at the edge of a shared wetland, woodland, and ecologically beneficial agriculture reserve, for a gross density of 1/20 to 1/40 acres ( $1 / 8$ to $1 / 16 \mathrm{ha})$. Average road density for the ecologically beneficial scenario was 0.8 linear miles per 640 developed acres (259 ha).

\section{Measuring possible water quality effects}

We employed a space for time substitution to compare the alternative development futures above to agricultural land cover for their water quality effects. If agricultural land were converted to conventional subdivisions, how would water quality be affected? If agricultural land were converted to ecologically beneficial subdivisions, how would water quality be affected? We expected that both the conventional futures and the ecologically beneficial futures would be likely to improve water quality compared with the conventional row-crop corn/soybean agriculture that characterizes southeastern Michigan. To assess the possible water quality effects of each type of exurban residential development future compared with agriculture, we measured the proportion of aggregated land cover classes on the alternative plans designed for each of the futures (Nassauer and Caddock, 1997). Using GIS coverages, low level aerial photography, and finally field inspection, we surveyed our study area catchments to identify several first-order catchments that exhibited land cover in similar proportions, according to the criteria in Table 1 .

Using these criteria, we selected six first-order catchments of the Huron Basin (ranging in size from $3 \mathrm{~km}^{2}$ to $12 \mathrm{~km}^{2}$, Table 2), that exhibited land cover to represent the same 
Table 1. Land cover proportions criteria for representing each type of landscape future

\begin{tabular}{ll}
\hline Landscape future types & Catchment land cover representativeness criteria \\
\hline Conventional agriculture & Impervious-not more than $10 \%$ \\
& Turf-not more than $10 \%$ \\
& Natural lands-not more than $30 \%$ \\
& Cropland-60\% or more \\
Conventional development & Impervious-15\% or more \\
& Turf-10\% or more \\
& Natural lands-not more than $50 \%$ \\
& Cropland-not more than $30 \%$ \\
Ecologically beneficial development & Impervious-not more than $15 \%$ \\
& Turf-not more than $10 \%$ \\
& Natural lands-70\% or more \\
Cropland-not more than $20 \%$
\end{tabular}

proportions as in each of three types of alternative exurban futures: conventional agriculture, conventional residential development, and residential developments designed to produce ecological benefits. We chose small catchments to minimize heterogeneity in land cover and first-order streams to minimize upstream influences. Two of the catchments were highly agricultural (Agri. 1 and 2), two were dominated by exurban residential development (Conv'l.1 and 2), and two contained an abundance of forests, wetlands, and perennial herbaceous areas characteristic of our designs for ecologically beneficial residential development (Eco. Ben. 1 and 2). None of the catchments was serviced by a sanitary or stormwater sewer or water infrastructure.

Of the six catchments, Agri.1 and 2 contain the highest percentages of agricultural land use at $63 \%$ and $78 \%$, Eco. Ben. 1 and 2 contain the highest percentages of forest, nonforested natural areas, and wetlands combined (71\% and 79\%), and Conv'l.1 and 2, contain the highest percentages of urban land uses (37\% and $17 \%$ ) and also have the greatest road densities of all catchments (Table 2). Table 2 compares the relationship of the land use/land cover data of the study catchments derived in the late 1990s with that from 1978. In all six catchments, urban land use increased. With increases in urban land use, all six basins experienced a decrease in percentage of forest and/or natural nonforested lands, and both agricultural catchments have experienced small decreases in the amounts of agricultural land use, changes that reflect exurbanization.

To evaluate the physical and biological condition of the streams draining the study catchments and compare the possible effects of the futures on stream condition, we selected a single aquatic ecology study site on each stream. Sites were chosen if stream flow was continuous at the location, if the site was accessible to the public, and if the site was considered representative of other stream locations visited in each study catchment. From each of the study sites, stream chemistry data were collected on three occasions during 1999 and 2000. Because of their geographic proximity to one another, all sites were assumed to respond similarly to climatic events that could lead to fluctuations in discharge. In December 1999, 
Table 2. Drainage area, road density, land use, and geology for the six study catchments based on GIS coverages

\begin{tabular}{lcccccc}
\hline Catchment type & Agri.1 & Agri.2 & Conv'l. 1 & Conv'l. 2 & Eco. Ben. 1 & Eco. Ben. 2 \\
Stream name & Arms & Mill & Woodruff & Nelson & Hay & N. Fk. Mill \\
Drainage area $\left(\mathrm{mi}^{2}\right)$ & 3.74 & 4.30 & 4.86 & 1.12 & 3.27 & 3.55 \\
Drainage area $\left(\mathrm{km}^{2}\right)$ & 9.69 & 11.14 & 12.59 & 2.91 & 8.48 & 9.20 \\
\hline
\end{tabular}

$\begin{array}{lrr}\text { Agriculture* (Agri.) } & 63 & 78 \\ \text { Urban* (Conv'1.) } & 5 & 9 \\ \text { Forest } & 18 & 7 \\ \text { Natural non forest } & 7 & 2 \\ \text { Wetland } & 7 & 4 \\ \text { Natural lands* } & 32 & 13 \\ \text { Parks and recreation } & 0 & 0 \\ \text { Barren } & 0 & 0 \\ \text { Water } & 0 & 0\end{array}$

$\begin{array}{rrrr}10 & 33 & 11 & 3 \\ 37 & 17 & 14 & 8 \\ 23 & 25 & 29 & 29 \\ 25 & 8 & 31 & 26 \\ 0 & 17 & 11 & 24 \\ 48 & 50 & 71 & 79 \\ 0 & 0 & 0 & 5 \\ 6 & 0 & 0 & 0 \\ 0 & 0 & 3 & 5\end{array}$

1978 Land use data (percentage)

\begin{tabular}{|c|c|c|c|c|c|c|}
\hline Agriculture & 65 & 83 & 9 & 33 & 11 & 3 \\
\hline Urban & 0 & 4 & 30 & 8 & 3 & 5 \\
\hline Forest & 20 & 11 & 24 & 25 & 40 & 34 \\
\hline Natural non forest & 10 & 2 & 31 & 17 & 37 & 29 \\
\hline Wetland & 5 & 0 & 0 & 17 & 6 & 18 \\
\hline Parks and recreation & 0 & 0 & 0 & 0 & 0 & 5 \\
\hline Barren & 0 & 0 & 6 & 0 & 0 & 0 \\
\hline Water & 0 & 0 & 0 & 0 & 3 & 5 \\
\hline \multicolumn{7}{|c|}{ Surficial geology (percentage) } \\
\hline Coarse & 0 & 33 & 100 & 0 & 100 & 100 \\
\hline Fine & 74 & 33 & 0 & 100 & 0 & 0 \\
\hline Medium end moraine & 26 & 0 & 0 & 0 & 0 & 0 \\
\hline Medium ground & 0 & 35 & 0 & 0 & 0 & 0 \\
\hline
\end{tabular}

*These land use categories were used to select the six study catchments. Natural Lands is the sum of Forest, Natural Non Forest and Wetlands.

after an extended period of minimal precipitation, data were collected to quantify the baseflow conditions of the study streams, data were collected in March 2000 to characterize the stream flow resulting from a significant snow melt and its associated runoff, and finally, during April 2000, data were collected three times over six days to characterize the stream flow resulting from a single spring storm and its associated runoff. On these occasions, water samples were collected at the sites and later analyzed in the laboratory for total suspended materials (TSM), total phosphorous (TP), and nitrate following standard methodology.

Aquatic macroinvertebrates were also collected from the study sites during the springs of 2000 and 2001 using standard bioassessment methods (Barbour et al., 1999). At each 
site, the various habitat types present were sampled for a length of time proportional to their abundance. Approximately 600 to 700 invertebrates were collected from each site and were all identified to genus except for chironomids, oligochetes, snails, and clams, which were identified to the lowest taxonomic level possible. Numerous measures quantifying the invertebrate assemblages of the study sites were later calculated including total number of taxa; number of Ephemeroptera, Plecoptera, and Trichoptera taxa; numbers of long-lived, intolerant, and clinger taxa; and finally, a biotic index (BI) describing the sensitivity of the macroinvertebrates of the study sites (Barbour et al., 1999). Many additional measures were made of the fishes, macroinvertebrates, and habitat at approximately 50 larger stream-sites, which provides a useful context for interpreting the results from these smaller, headwater sites.

\section{Measuring public perception}

To compare public perceptions of the alternative futures, we surveyed 336 residents of southeastern Michigan. Most respondents (231) used a web-based survey in which they saw images on their own monitors; 105 responded to a paper-and-pencil survey in which they saw images projected as slides during meetings. Not all of these respondents provided an image rating for every image. Each respondent viewed 19 simulations: 13 depicting alternative futures for residential parcel landscapes and 6 depicting alternative futures for exurban subdivisions. This paper draws only on responses to the 2 ecologically beneficial residential and 2 conventional residential subdivision futures.

Respondents received no additional information about the price or ecological benefits of each simulated subdivision landscape. They were asked to rate each landscape on seven- point bi-polar adjective scales using the paired adjectives natural-artificial, attractiveunattractive, neat-messy, and good care-poor care (only the attractiveness data were analyzed for this study). Respondents were told that a rating of " 4 " would be neutral. In each case, respondents were asked to rate the scene in the image that they saw based on what the words on the scales meant to them and in comparison to the residential landscapes they knew in their own county. Respondents were asked to rate the subdivision designs as though they were viewing the landscape from the window of a home they might purchase in the neighborhood depicted in the slides.

Our survey was an opportunity sample in which we targeted homeowners in two sample strata: environmental group members and those who did not belong to environmental groups, whom we termed the "general public". We use environmental group membership as a surrogate for environmental knowledge, and we suggest that this surrogate may be a useful way to anticipate how public perceptions may change over time if the general public becomes increasingly interested and knowledgeable about environmental issues. Homeowners constituted $85 \%$ of our respondents. Their average age was 44.7 , with a range of 18-80. Slightly more than half the respondents were women: $60 \%$ female. Despite the slight gender disparity, there was no detectable difference in responses based on gender. The survey respondents were well educated, with about $81 \%$ having earned a college degree. The majority had a household income in the range of $\$ 50,000-\$ 119,999$. About $30 \%$ of the total sample reported living in the city, $30 \%$ in the suburbs, and $20 \%$ in non-farm rural 
areas. We asked respondents to report the mix of land uses near their home. The largest response was single family homes mixed with multifamily homes and retail (33\%). Many lived near single family homes only $(26 \%)$ or near single family homes mixed with farms $(23 \%)$.

Slightly less than half of the respondents reported being members of environmental groups. There were few differences between the environmental group members and the general public group in other demographics. While environmental group members have somewhat higher average levels of education, average income is the same for both groups. Each group was about 60\% women. Environmental group membership was the only demographic variable that produced a pattern of significant differences in ratings of residential development alternatives.

The survey sample was recruited through a series of notices to electronic mailing lists, a newspaper notification, and by word of mouth. During administration of the questionnaire, respondents viewed full-screen digital imaging simulations of each of the futures as they would be seen from other homes in the area, and they rated their perceptions on several sevenpoint bipolar adjective scales, including attractive-unattractive. To prevent bias, neither the design goals nor the ecological benefits of the landscape design treatments were presented to respondents before or during perception rating. Each set of alternative future images simulated for given base site place was presented in sequence, with two different random slide orders within and between the sets.

\section{Results}

\section{Chemistry}

Streams draining catchments representing ecologically beneficial development (EBD) futures had lower levels of nitrate than streams in agricultural catchments at baseflows and following snowmelt. Also, in response to a spring storm, streams draining EB catchments had lower concentrations of TSM, TP, and nitrate than those in either the agricultural or conventionally developed $(\mathrm{CD})$ catchments.

Figure 3 displays the concentrations of TSM, TP, and nitrate for the study streams at baseflow in December 1999 and for the snowmelt of March 2000. The trends among the study sites were similar for both events. For example, levels of TSM were relatively low at most sites during baseflow and snowmelt, while levels of TP were generally low during baseflow and slightly higher during snowmelt.

Concentrations of nitrate, however, were much greater for the streams in agricultural catchments at both baseflow and snowmelt than for the streams of the EBDor CD catchments. For both events, nitrate concentrations were an order of magnitude greater in the streams draining the agricultural catchments.

The differences in chemistry of the streams draining EBD catchments versus those draining agricultural and CD catchments were greatest during the spring storm of April 2000. From the beginning of the storm on April 20 through the last day that chemistry was monitored on April 25, levels of TSM and TP were higher at the sites draining CD and 
12/21/99 -- Baseflow

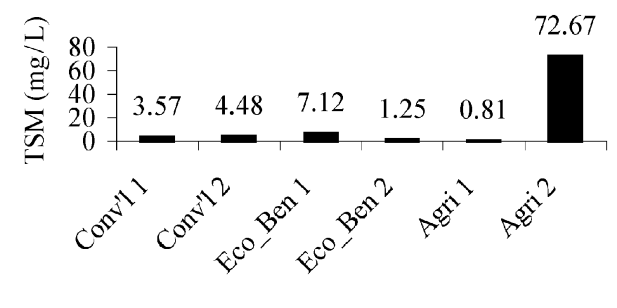

12/21/99 -- Baseflow

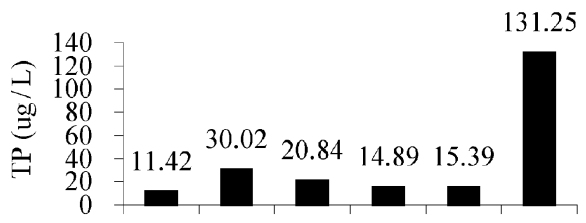

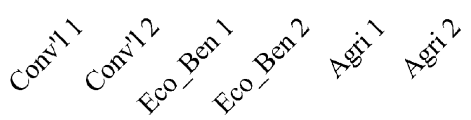

12/21/99 -- Baseflow

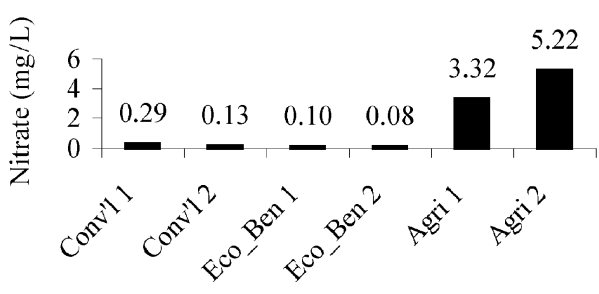

3/1/00 -- Snowmelt

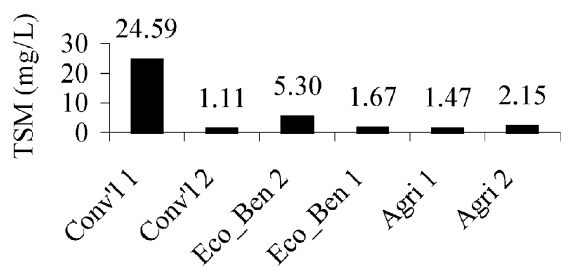

3/1/00 -- Snowmelt

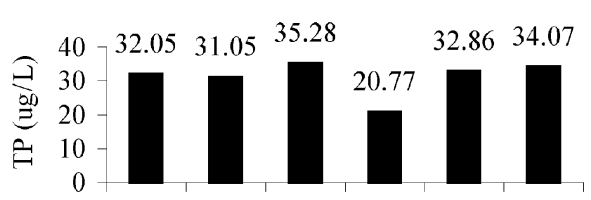

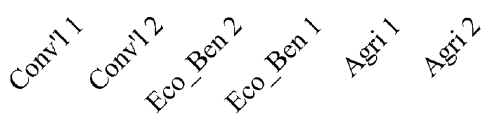

3/1/00 -- Snowmelt

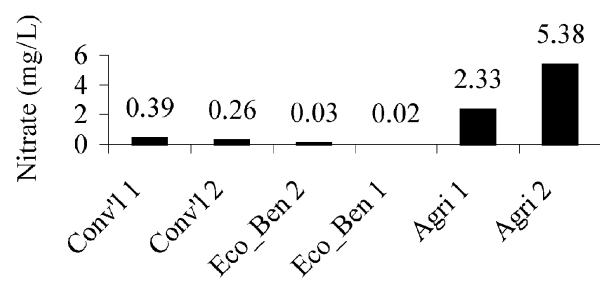

Figure 3. Total suspended material (TSM), total phosphorus (TP), and nitrate for the six study catchments during baseflow, December 1999, and snowmelt, March 2000.

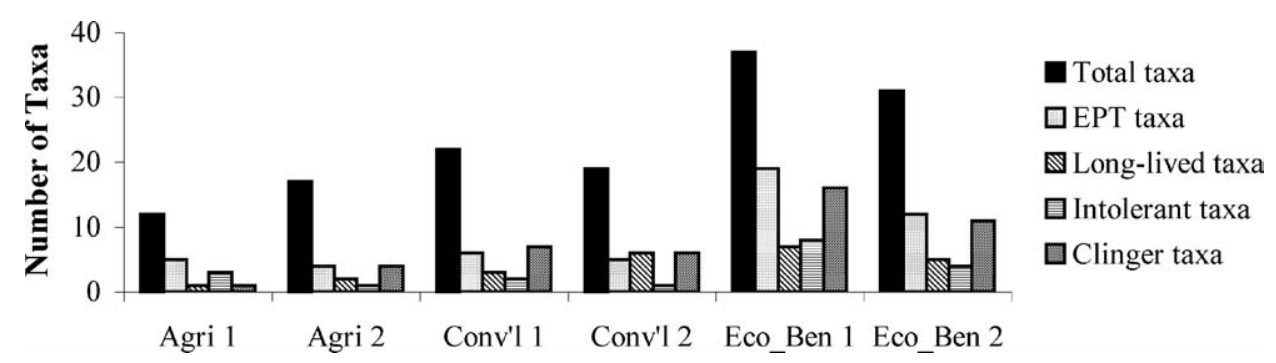

Figure 4. Aquatic macroinvertebrate taxa collected from the six study catehments. 
agricultural catchments (figure 3). For example, on April 20, concentrations of TSM measured at the EBD streams were $11.56 \mathrm{mg} / \mathrm{l}$ and $48.57 \mathrm{mg} / \mathrm{l}$, respectively, while those in the agricultural and CD catchments ranged from $62.03 \mathrm{mg} / \mathrm{l}$ to $315.85 \mathrm{mg} / \mathrm{l}$. Also, on April 25, TP concentrations in the EBD streams were $17.30 \mu \mathrm{g} / \mathrm{l}$ and $15.72 \mu \mathrm{g} / \mathrm{l}$ while those in the other catchments ranged from $22.36 \mu \mathrm{g} / \mathrm{l}$ to $37.54 \mu \mathrm{g} / \mathrm{l}$. Levels of nitrate were again substantially higher in the streams draining agricultural catchments than in those draining either the EBD or CD catchments.

\section{Aquatic macroinvertebrates}

Streams draining ecologically beneficial catchments supported more total macroinvertebrate taxa as well as more sensitive macroinvertebrate taxa than streams draining agricultural or conventionally-developed catchments. First, Eco.Ben. 1 and 2 supported 37 and 31 total taxa, respectively, while the streams of the other catchments only supported from 12 to 22 taxa (figure 4). Streams of the Eco.Ben. 1 and 2 catchments also had more EPT taxa, which is a measure of mayflies, stoneflies, and caddisflies known to prefer relatively welloxygenated streams with diverse habitats; long-lived taxa, which are assumed to require relatively stable stream environments; taxa that are intolerant of a variety of water quality pollutants and variable flow regimes; and clinger taxa, which require stream cover usually supplied by bank vegetation.

\section{Public perception}

Reported in Table 3 are the respondents' perceptions of the attractiveness of the alternative residential futures. Overall, the ecologically beneficial scenario was perceived as more attractive than the conventional scenario by both environmental group members and the general public, and ratings from both groups rank the futures' attractiveness similarly.

Environmental group members and the general public had significantly different perceptions of the attractiveness of the conventional subdivision futures, but both groups gave both the conventional futures lower ratings than either of the ecologically beneficial futures. The

Table 3. Mean perceived attractiveness of alternative exurban development futures

\begin{tabular}{|c|c|c|c|c|}
\hline \multirow[b]{2}{*}{ Perceived attractiveness } & \multicolumn{2}{|c|}{$\begin{array}{c}\text { Conventional } \\
\text { subdivision designs }\end{array}$} & \multicolumn{2}{|c|}{$\begin{array}{l}\text { Ecologically beneficial } \\
\text { subdivision designs }\end{array}$} \\
\hline & Conv'l. A & Conv'l. B & Eco_Ben. C & Eco_Ben. D \\
\hline $\begin{array}{l}\text { Environmental group members } \\
\quad \text { response } n=184\end{array}$ & $3.11^{*}$ & $2.46^{* *}$ & 5.51 & $6.46^{*}$ \\
\hline $\begin{array}{l}\text { General public } \\
\quad \text { response } n=131\end{array}$ & $3.72^{*}$ & $2.91^{* *}$ & 5.44 & $5.69^{*}$ \\
\hline
\end{tabular}

$*<.01$ probability ( $\mathrm{F}$ test in ANOVA) difference between groups.

$* *<.02$ probability ( $\mathrm{F}$ test in ANOVA) difference between groups. 
general public found the conventional designs significantly more attractive than did the environmental group members, however. For the ecologically beneficial futures, environmental group members had a significantly higher average rating of the future rated most attractive by both groups, the large lot indigenous cover ecologically beneficial alternative (Table 3 ; also see figure 2). For the other ecologically beneficial design, there was no significant difference in attractiveness ratings by environmental group members and the general public.

\section{Conclusions}

Our method for linking empirical measures of water quality and public perception with innovative future land covers for residential land use suggests a means of establishing a range of assumptions related to land use in both hydrologic models and metropolitan growth models. It also underscores the desirability of including innovative, normatively superior ideas about land cover design in such models when their purpose is to anticipate the future consequences of land use decisions.

In addition, our results contribute to the discussion of whether and how ecologically superior landscapes are valued by the public, and whether such ecologically beneficial land use choices can be culturally sustainable. For this set of ecologically-beneficial development futures, public perception of attractiveness is consistent with measures of aquatic ecological health; landscapes that produced the highest water quality also were perceived as most attractive. Rankings of stream chemistry results for the alternative residential development scenarios (figures 3 and 4) are similar to rankings of public perception results for exurban residential development (Table 3). The ecologically beneficial exurban development alternatives were perceived as more attractive than the conventionally developed alternatives, and the first-order stream catchments that represented land cover of the ecologically beneficial development alternatives delivered lower amounts of nitrates, total phosphorous, and total suspended materials to the streams, and they supported more total macroinvertebrate taxa as well as more sensitive macroinvertebrate taxa.

These results suggest opportunities for land use policy. While there is wide public disagreement about the control of conventional exurban residential development, or sprawl, there may be greater hope for public agreement on the desirability of innovative forms of exurban residential development that can deliver ecological benefits. While the low-density development we show in this project would clearly have societal costs if it were applied as a universal panacea for sprawl, it presents a desirable compromise where development that enhances ecological quality is preferable to existing agricultural uses or conventional alternatives, and where other forms of land cover control, like land purchase, or wholesale changes in agricultural practices are not practical. Where a larger public benefit is realized by protecting water quality or habitat, as demonstrated in this project by empirical data for aquatic ecosystems, low-density development of the appropriate land cover may be a desirable form of land use change from the perspective of public perception and from the perspective of ecological health. 


\section{Note}

1. NSF EAR Grant no. 9900679. Development and Testing of a Decision-Support System for River Restoration. D. Allan, G. Helfand, J. Nassauer.

\section{References}

Alberti, M. (1999) Urban patterns and environmental performance: What do we know? Journal of Planning Education and Research 19, 151-163.

Arendt, R. (1996) Conservation Design for Subdivisions: A Practical Guide to Creating Open Space Networks. Washington, D. C., Island Press.

Arendt, R. (1999) Growing Greener: Putting Conservation into Local Plans and Ordinances. Washington, D.C., Island Press.

Arnold, C.L.J. and Gibbons, C.J. (1996) Impervious surface coverage: The emergence of a key environmental indicator. Journal of the American Planning Association 62, 243-258.

Barbour, M.T., Gerritsen, J., Snyder, B.D. and Stribling, J.B. (1999) Rapid Bioassessment Protocols for Use in Streams and Wadeable Rivers: Periphyton, Benthic Macroinvertebrates, and Fish. U.S. Environmental Protection Agency, EPA 841-B-99-002, Washington, D.C.

Booth, D.B. and Jackson, C.R. (1997) Urbanization of aquatic systems: Degradation thresholds, stormwater detection, and the limits of mitigation. Journal of the American Water Resources Association 33(5), 10771090.

Burges, S.J., Wigmosta, M.S. and Meena, J.M. (1998) Hydrological effects of land-use change in a zero-order catchment. Journal of Hydrologic Engineering 3(2), 86-97.

Cappiella, K. and Brown, K. (2001). Impervious Cover and Land use in the Chesapeake Bay Watershed. Center for Watershed Protection, Ellicot City, Maryland.

Crowder, D.W. and Diplas, P. (2002) Assessing changes in watershed flow regimes with spatially explicit hydraulic models. Journal of the American Water Resources Association 38(2), 397-408.

Forsyth, A. (2002) Planning lessons from three U.S. new towns of the 1960s and 1970s: Irvine, Columbia, and The Woodlands. Journal of the American Planning Association 68(4), 387-415.

Girling, C. and Kellett, R. (2002). Comparing stormwater impacts and costs on three neighborhood plan types. Landscape Journal 21(1): 100-109.

Gregory, K.J. and Davis, R.J. (1993). The perception of riverscape aesthetics: An example from two Hampshire rivers. Journal of Environmental Management 39(3), 171-187.

Gobster, P.H. (1999) An ecological aesthetic for forest landscape management. Landscape Journal 18(1), 54-64.

Gove, N.E., Edwards, R.T. and Conquest, L.L. (2001) Effects of scale on land use and water quality relationships: a longitudinal basin-wide perspective. Journal of the American Water Resources Association 37(6), 1721-1734.

House, M. and Fordham, Maureen (1997). Public perceptions of river corridors and attitudes towards river weorks. Landscape Research 22(1), 25-44.

Hulse, D., Eilers, J., Freemark, K., Hummon, C. and White, D. (2000) Planning alternative future landscapes in Oregon: evaluating effects on water quality and biodiversity. Landscape Journal 19(1/2), 1-19.

Hunsaker, C.T. and Levine, D.A. (1995) Hierarchical approaches to the study of water quality in rivers. BioScience 45(3), 193-203.

Jennings, D.B. and Jarnagin, S.T. (2002) Changes in anthropogenic impervious surfaces, precipitation and daily streamflow discharge: A historical perspective in a mid-atlantic watershed. Landscape Ecology 17, 471-489.

Jia, Y., Ni, G., Yoshitani, J., Kawahara, Y. and Kinouchi, T. (2002) Coupling simulation of water and energy budgets and analysis of urban development impact. Journal of Hydrologic Engineering 7(4), 302-311.

Kaplan, R., and Kaplan, S. (1989). The Experience of Nature. Cambridge, Cambridge University Press.

Klein, R.D. (1979) Urbanization and stream quality impairment. Water Resources Bulletin 15(4), 948-963.

Michigan Department of Environmental Quality (MDEQ). (1997) Qualitative Biological and Habitat Survey Protocols for Wadable Streams and Rivers. Surface Water Quality Division, Great Lakes and Environmental Assessment Section, Lansing, Michigan. 
Martin, J.F., Reyes, E., Paul Kemp, G., Mashriqui, H. and Day, J.W. Jr. (2002) Landscape modeling of the Mississippi delta. BioScience 52(4), 357-365.

Miller, S.N., Kepner, W.G., Mehaffey, M.H., Hernandez, M., Miller, R.C., Goodrich, D.C., Devonald, K.K., Heggem, D.T. and Miller, W.P. (2002) Integrating landscape assessment and hydrologic modeling for land cover change analysis. Journal of the American Water Resources Association 38(4), 915-929.

Moglen, G.E. and Beighley, R.E. (2002) Spatially explicit hydrologic modeling of land use change. Journal of the American Water Resources Association 38(1), 241-253.

Nassauer, J.I. (1992) The appearance of ecological systems as a matter of policy. Landscape Ecology 6(4), 239-250. Nassauer, J.I. (1995). Messy ecosystems, orderly frames. Landscape Journal 14(2), 161-170.

Nassauer, J.I. (1999) Ecological Retrofit. Landscape Journal 17(2), 15-17.

Nassauer, J.I., Kosek, S.E. and Corry, R.C. (2001) Meeting public expectations with ecological innovation in riparian landscapes. Journal of the American Water Resources Association 37(6), 1-5.

Nassauer, J.I. and Caddock, A. (1997) Local Analyses and Development Scenarios. MN Agricultural Experiment Station \#39-077. University of Minnesota. St. Paul, MN.

Nassauer, J.I. and Corry, R.C. (2004). Using normative scenarios in landscape ecology. Landscape Ecology. In Press.

Parsons, R. (1995) Conflict between ecological sustainability and environmental aesthetics: Conundrum, canard or curiosity. Landscape and Urban Planning 32(1), 227-244.

Schueler, T. (1994) The importance of imperviousness. Watershed Protection Techniques 1(3), 100-111.

Southeast Michigan Coalition of Governments. (2001) 2001 Annual Report.

Steiner, F., McSherry, L., Brennan, D. and Soden, M. (1999) Concepts for alternative suburban planning in the northern Phoenix area. Journal of the American Planning Association 65 (2), 207-222.

Steinitz, C. (1990) Toward a sustainable landscape with high visual preference and high ecological integrity: The Loop Road in Acadia National Park, USA. Landscape and Urban Planning 19, 231-250.

Wang, L., Lyons, J., Kanehl, P. and Bannerman, R. (2001) Impacts of urbanization on stream habitat and fish across multiple spatial scales. Environmental Management 28(2), 255-266. 